\title{
Separating the wheat from the chaff-COVID-19 in a German emergency department: a case-control study
}

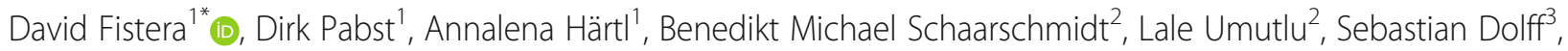
Carola Holzner ${ }^{1}$, Clemens Kill ${ }^{1}$ and Joachim Risse ${ }^{1}$

\begin{abstract}
Background: COVID-19 pandemia is a major challenge to worldwide health care systems. Whereas the majority of disease presents with mild symptoms that can be treated as outpatients, severely ill COVID-19 patients and patients presenting with similar symptoms cross their ways in the emergency department. Especially, the variety of symptoms is challenging with primary triage. Are there parameters to distinguish between proven COVID-19 and without before? How can a safe and efficient management of these inpatients be achieved?

Methods: We conducted a retrospective analysis of 314 consecutive inpatient patients who presented with possible symptoms of COVID-19 in a German emergency department between March and April 2020 and were tested with a SARS-Cov-2 nasopharyngeal swab. Clinical parameters, Manchester Triage System categories, and lab results were compared between patients with positive and negative test results for SARS-Cov-2. Furthermore, we present the existing COVID-19 workflow model of the university hospital in Essen which proved to be efficient during pandemia.

Results: Forty-three of the 314 patients (13.7\%) were tested positive for COVID-19 by SARS-Cov-2 nasopharyngeal swab. We did not find any laboratory parameter to distinguish safely between patients with COVID-19 and those with similar symptoms. Dysgeusia was the only clinical symptom that was significantly more frequent among COVID-19 patients.

Conclusion: Dysgeusia seems to be a typical symptom for COVID-19, which occurred in 14\% of our COVID-19 patients. However, no valid parameters could be found to distinguish clinically between COVID-19 and other diseases with similar symptoms. Therefore, early testing, a strict isolation policy, and proper personal protection are crucial to maintain workflow and safety of patients and ED staff for the months to come.
\end{abstract}

Trial registration: German Clinical Trials registry, DRKS00021675

Keywords: COVID-19, Triage, Clinical symptoms, Emergency department, SARS-Cov-2

\footnotetext{
* Correspondence: David.fistera@uk-essen.de

${ }^{1}$ Center of Emergency Medicine, University Hospital Essen, Hufelandstrasse

55, 45147 Essen, Germany

Full list of author information is available at the end of the article
}

(c) The Author(s). 2020 Open Access This article is licensed under a Creative Commons Attribution 4.0 International License, which permits use, sharing, adaptation, distribution and reproduction in any medium or format, as long as you give appropriate credit to the original author(s) and the source, provide a link to the Creative Commons licence, and indicate if changes were made. The images or other third party material in this article are included in the article's Creative Commons licence, unless indicated otherwise in a credit line to the material. If material is not included in the article's Creative Commons licence and your intended use is not permitted by statutory regulation or exceeds the permitted use, you will need to obtain permission directly from the copyright holder. To view a copy of this licence, visit http://creativecommons.org/licenses/by/4.0/. The Creative Commons Public Domain Dedication waiver (http://creativecommons.org/publicdomain/zero/1.0/) applies to the data made available in this article, unless otherwise stated in a credit line to the data. 


\section{Introduction}

The COVID-19 pandemic with at more than 6.5 million cases worldwide and more than 397,000 fatalities (date 07 June 2020) is an unprecedent situation for society and health care [1]. Although, most infections are not severe [2-5], about 5\% develop a critical disease with respiratory failure, shock, or multiorgan dysfunction [5]. The overall case fatality rate is estimated at around 0.7 to $2.3 \%[5,6]$. Pneumonia appears to be the most frequent severe manifestation of infection $[2,6]$. Additional COVID-19-induced coagulopathy might play an important role in COVID-19-related death [7].

Whereas the majority of patients presents with mild symptoms [2-5] and can be treated as outpatients, severely ill COVID-19 patients and patients with similar symptoms cross their way in the emergency department (ED). Due to the high infectiousness of SARS-Cov-2, it is crucial to separate patients with suspicion of COVID-19 and other patients as soon as possible to avoid further spread of the infection. Especially, the variety of symptoms in COVID-19 patients is challenging for the primary triage in the ED: fever, fatigue, dry cough, anorexia, myalgias, dyspnea, sputum production, and olfactory and taste disorders are the most frequent symptoms $[2,8]$.

Particular laboratory features like lymphopenia, elevated liver enzymes, elevated lactate dehydrogenase, Creactive protein, elevated $\mathrm{D}$-dimer, elevated prothrombin time, elevated troponin, and acute kidney injury have been associated with worse outcomes [9, 10]. However, data about possible parameters to distinguish between COVID-19 and other patients are sparse.

Therefore, we conducted a retrospective analysis to identify clinical parameters and laboratory features which could improve early triage between patients with and without COVID-19.

\section{Methods \\ Patients}

We performed a retrospective, single-center case-control study that included all inpatient patients with possible symptoms of COVID-19 who were admitted to the emergency department between March and April 2020 and were tested by nasopharyngeal swab for SARS-Cov2. At least one symptom upon arrival to the ED out of the following was required for inclusion: dyspnea, sore throat, cough, fever, headache, fatigue, myalgia, chest pain, nausea, diarrhea, and/ or dysgeusia. Patients without any of the mentioned symptoms were excluded as well as those without valid nasopharyngeal swab results. Our study was approved by the institutional ethics committee and informed consent was waived (file number: 20-9310-BO, date: 6 May 2020). The study was registered at the German Clinical Trials registry (trial number: DRKS00021675, date 8 May 2020).
Patients and the public were not involved in this study.

\section{COVID-19 ED workflow model Essen}

To establish a central COVID-19 pandemia care center within the city of Essen (560,000 inhabitants), the university hospital was required to develop a safe and efficient workflow in the emergency department.

A separate outpatient COVID-19 ED was established next to the non-trauma ED for all walking patients with quick workflow filtering out those who need inpatient care. To streamline patient workup, the existing ED isolation capacities were extended by a fourteen bed holding area for patients under evaluation for COVID-19; three more isolation units were established for those with proven COVID-19 disease, as well as a separate intermediate care unit and ICU with ECMO available (Fig. 1).

Our workflow (Fig. 2) combines a definite diagnosis/ rule out strategy for COVID-19 with a high level of isolation measures. All patients with symptoms suggestive of COVID-19 were isolated upon arrival to the ED. After initial triage and vital parameters, unstable patients were transferred to a shock room/ COVID-19 ICU.

All patients were tested for COVID-19 by a SARSCov-2 nasopharyngeal swab (ViroCult ${ }^{\oplus}$, Medical Wire \& Equipment Co. Ltd., Corsham, Wiltshire, UK). To detect SARS-CoV-2, a RT-PCR (SARS-CoV-2 RT-PCR Kit 1.0, Altona Diagnostics GmbH, Hamburg, Germany) was performed [11]. Additional laboratory testing and CT pulmonary angiography were performed when symptoms of lower respiratory tract involvement occurred. Retesting or additional bronchoscopy/ CT scan could be added in case of ongoing suspicion and negative swab testing. Strict isolation measures were kept until COVID-19 was definitely ruled out. From the onset of pandemia, all ED employees had to wear faceshields and FFP3 masks whenever in contact with any patient irrespective of symptoms suggestive for COVID-19 and keeping distance to each other while wearing a regular mask inside the ED.

\section{Parameters}

We compared and analyzed clinical parameters, Manchester Triage System (MTS) categories, and laboratory parameters between patients with negative and patients with positive swab results for SARS-CoV-2.

Clinical parameters were symptoms upon arrival comprising dyspnea, sore throat, cough, fever, headache, fatigue, myalgia, chest pain, nausea, diarrhea, and dysgeusia.

Laboratory results were white blood cell count, lymphocytes, C-reactive protein, procalcitonine, glomerular filtration rate, creatinine, troponine, and D-dimers. 


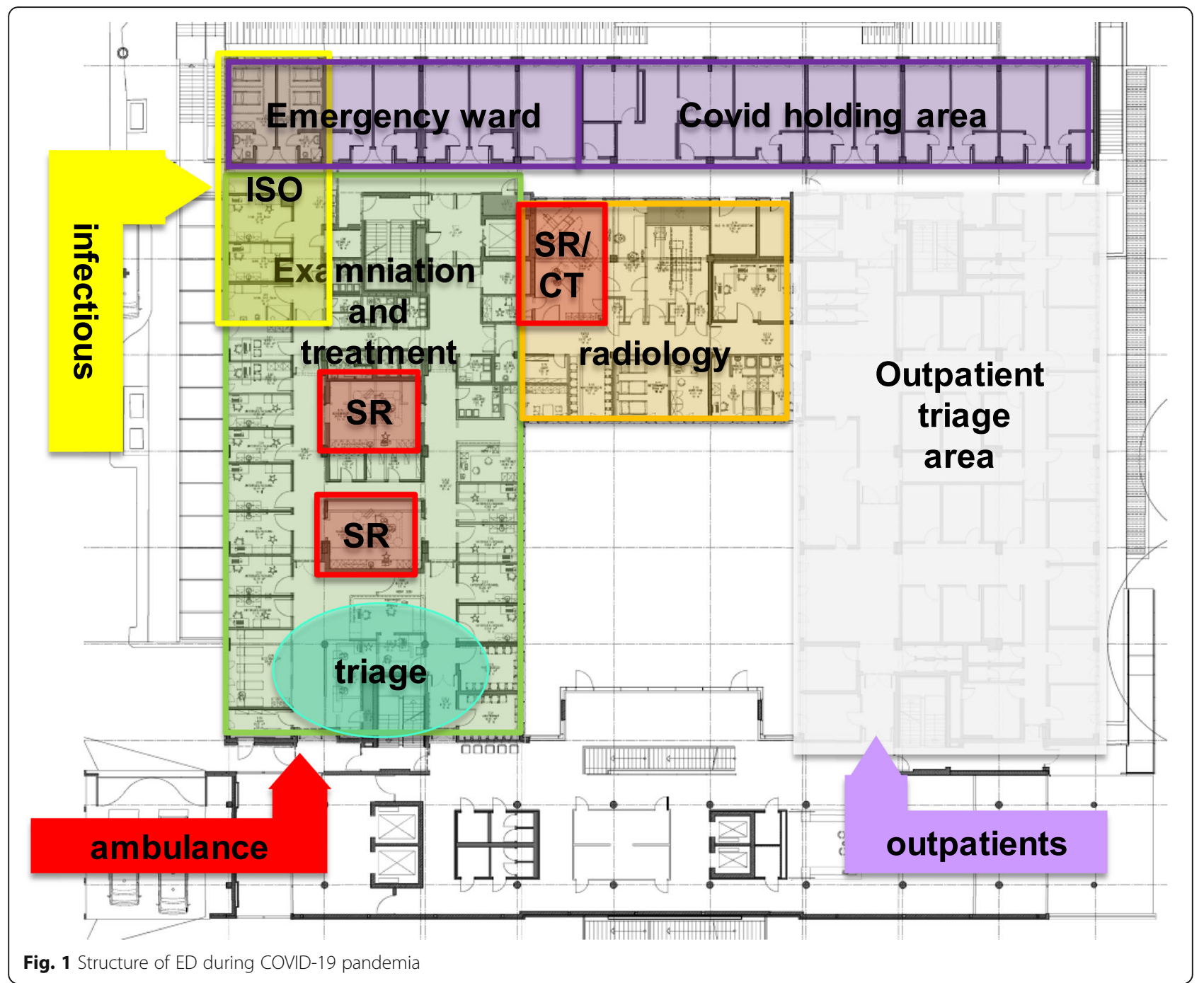

Patient data were obtained through the electronic medical record (ERPath, eHealth-Tec Innovations $\mathrm{GmbH}$, Berlin, Germany; Medico, Cerner Health Services GmbH, Idstein, Germany).

Missing data that could not be extracted from patients' records were excluded from statistical analysis.

\section{Statistical analyses}

We used a $t$ test to evaluate metric data. Data were tested by Levene's test to assess the equality of variances. In case of unequal variances, Welch's $t$ test was performed to analyze metric data. Results were reported as mean \pm standard deviations for continuous variables. Pearson's $x^{2}$ test or the Fisher's exact test was used to evaluate categorical data. Results for categorical variables were reported as percentages. All data were analyzed using SPSS, version 26 (IBM, Armonk, NY, USA). Statistical significance was defined as two-tailed $p<0.05$.

\section{Results}

A total of 314 patients (mean age $66 \pm 17.7$ years; 118 female (37.6\%)) were included in the analysis. Baseline characteristics are summarized in Table 1 . According to the MTS, 52 patients were classified as "red" (16.6\%), 28 patients as "orange" (8.9\%), 118 patients as "yellow" (37.8\%), 111 patients as "green" (35.4\%), and 3 patients as "blue" (1.0\%).

Forty-three patients (13.7\%) were tested positive for SARS-Cov-2 by nasopharyngeal swab. Results after comparison of the COVID-19 patients and the patients with negative swab are listed in Table 2.

Of the 271 with negative test results, 55 underwent repeated testing due to ongoing suspicion of COVID-19. Two of those $55(3.6 \%)$ revealed to be positive in the course of clinical treatment but were not included in our primary analysis of COVID-19 positive patients.

Of all COVID-19 patients, 14\% (6/43) reported dysgeusia, while this clinical feature was only present in 
COVID-19:

inpatient workflow University hospital Essen

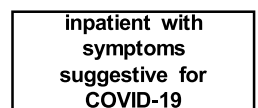

COVID-19

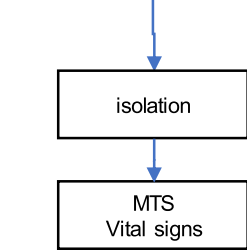

\section{Abbreviations:}

ED: emergency department

MTS: Manchester Triage Scale

PCR: polymerase chain reaction
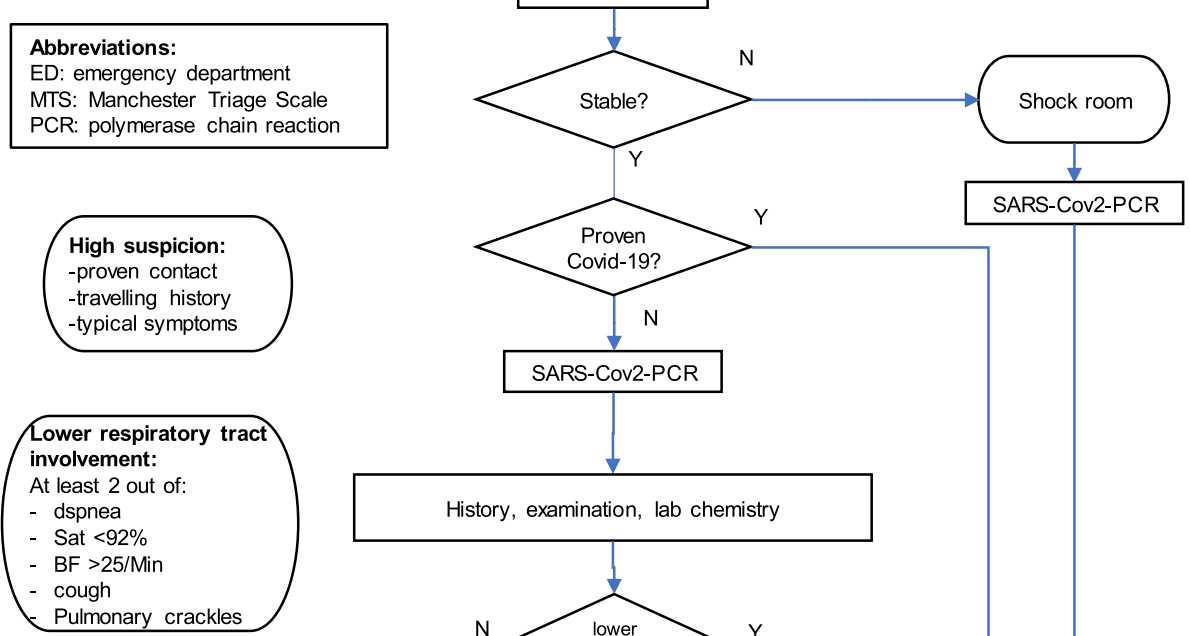

istory, examination, lab chemistry
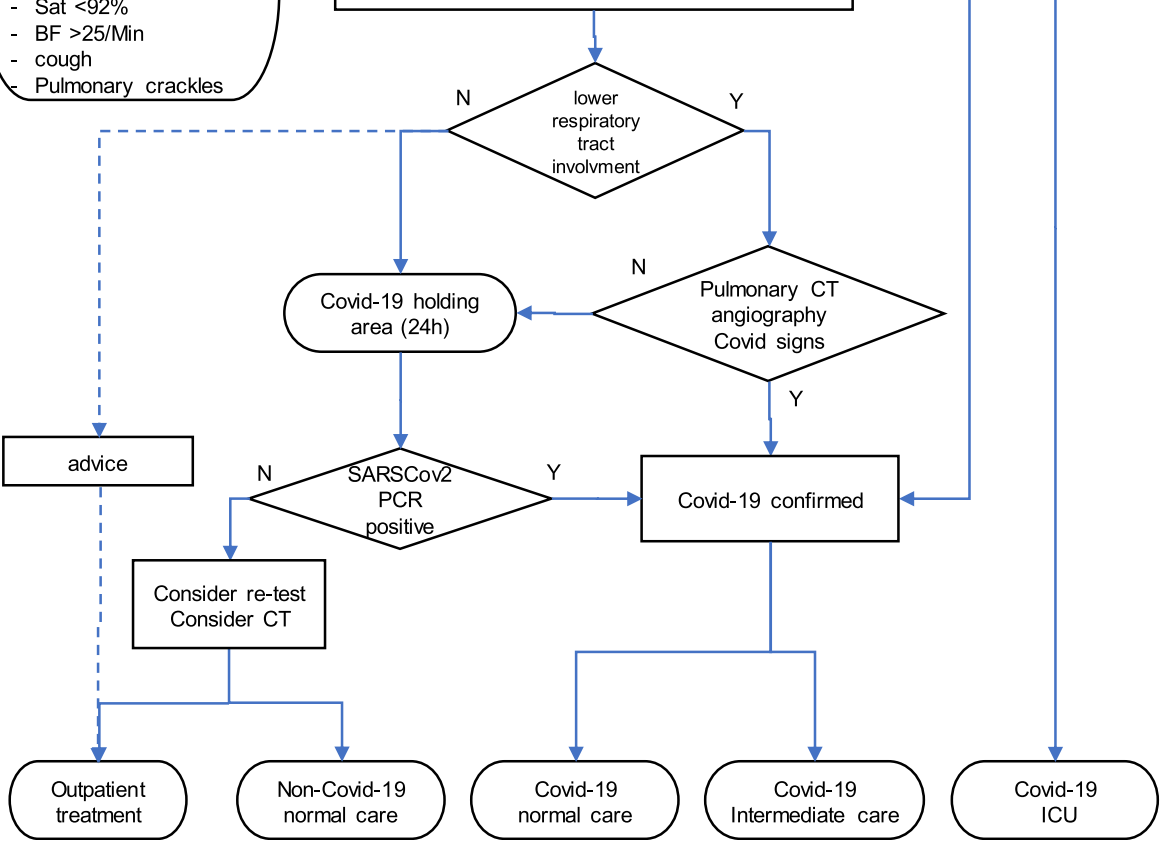
lower tract

Fig. 2 Workflow inpatient COVID-19

$1.5 \%(4 / 271)$ of non-COVID-19 patients $(p=0.001)$. Significant differences between the two groups were not observed for other clinical features (Fig. 3).

Patients with COVID-19 had significantly less preexisting renal disorders $(9.3 \%$ vs $27.0 \%$; $p$ value 0.012 ). No significant differences were observed for the presence of a preexisting cardiac or pulmonary disorder, previous thrombosis, or pulmonary embolism and oncological diseases between COVID-19-positive and COVID-19-negative patients.
There were significantly more active smokers in the non-COVID-19 group than in the group with COVID19 -positive patients $(13.7 \%$ vs $2.3 \% ; p=0.034)$. However, the number of patients with an unknown smoking status was, although not significantly, also higher in the nonCOVID-19 group than in the group tested positively (58.3\% vs $16.0 \% ; p=0.154)$.

The mortality of COVID-19 patients admitted to our hospital via the ED was 18.6\%, which was not 
Table 1 Characteristics of patients who were admitted to the emergency department due to symptoms suspicious for COVID-19

\begin{tabular}{|c|c|c|c|c|}
\hline & All $(n=314)$ & COVID-19 pos. $(n=43)$ & No-COVID-19 $(n=271)$ & $p$ value \\
\hline Age, mean ( $\pm S D$, range) & $66( \pm 17.72,22-97)$ & 71 ( \pm 17.03; 23-94) & 65 ( \pm 17.70; 22-97) & 0.057 \\
\hline Male gender, $n(\%)$ & $196(62.4)$ & $28(65.1)$ & $168(62.0)$ & 0.694 \\
\hline \multicolumn{5}{|l|}{ Manchester triage, $n(\%)$} \\
\hline Red & $52(16.6)$ & $4(9.3)$ & $48(17.7)$ & 0.160 \\
\hline Orange & $28(8.9)$ & $3(7.0)$ & $25(9.2)$ & 0.622 \\
\hline Yellow & $118(37.8)$ & $13(30.2)$ & $105(39.0)$ & 0.269 \\
\hline Green & $111(35.4)$ & $23(53.5)$ & $88(32.5)$ & 0.008 \\
\hline Blue & $3(1.0)$ & $0(0)$ & $3(1.1)$ & 0.487 \\
\hline
\end{tabular}

significantly higher than patients admitted with similar symptoms but negative COVID-19 result $(11.1 \%)(p=$ $0.159)$.

In the group of the COVID-19 patients, 18 patients (41.9\%) were treated with oxygen upon admission in the emergency department. However, this was not significantly different to the 77 patients $(28.5 \%)$ of the nonCOVID-19 group who were supported with oxygen.

We could not find any significant differences regarding to vital parameters and laboratory values between the two groups (Table 2)

\section{Discussion}

Forty-three patients (13.7\%) of our 314 patients were tested positive for COVID-19 by pharyngeal swab.

In our study, dysgeusia was the only clinical finding that was significantly more frequent in COVID-19 patients. Unfortunately, we did not identify further clinical findings, laboratory parameters, or vital signs to distinguish between patients positive for COVID-19 and the negative tested ones.

Gao et al. showed significant differences in D-Dimer and $\mathrm{C}$-reactive protein (CRP) between mild and severe cases of COVID-19 [12]. Also, lymphopenia and higher $\mathrm{LDH}$ values have been described to be associated with higher rate of ICU admissions in patients with COVID19 [13]. Mardani et al. published a small study with 200 patients in which they suggest that level of LDH, CRP, ALT, and neutrophils could be used to predict the result of COVID-19 test [14]. However, convincing data of larger studies that show the use of predicting laboratory parameters are sparse.

In our study, we observed three findings that seemed to be associated with COVID-19:

a. Patients with COVID-19 had more often dysgeusia. Six COVID-19 patients (14.0\%) reported this symptom, whereas only 4 (1.5\%) of the non-COVID-19 group. Reduced olfaction and decreased sense of taste was reported especially after the viral outbreak reached Europe and might be quite pathognomonic for COVID-19 [15, 16]. However, dysgeusia was only present in a small proportion of cases and, thus, is a specific but not sensitive symptom.

b. Interestingly, in this study, a history of renal failure was associated with a lower likelihood to be tested positive for COVID-19. This result does not match with the current literature. In previous studies, medical history of immunosuppressive and cardiovascular diseases, including renal disorders, shows a higher risk for severe COVID-19 infection and need for hospital admission in COVID-19 patients $[5,6]$. However, in our cohort, patients with positive COVID-19 test were, even if not significantly, younger compared to the negative group. In general, older patients are more likely to have renal disorders [17], and thus, patient age might serve as a confounder in our analysis. Gao et al. found an association with the treatment of hypertension and severe COVID-19 infection, including COVID-19 mortality [18]. In their study, antihypertensive treatment seems to protect patients from severe COVID-19 infection. Hypertension is associated with renal disorders [17]. In general, patients with renal failure may use more antihypertensive medication than patients without renal disorders. Therefore, this medication could protect them from severe COVID-19 infection needing hospital admission. However, we are aware that this is daring thesis and larger studies are needed to elucidate the complex interaction of renal function, antihypertensive medication, and COVID-19 infection.

c. In our study, there tended to be less active smokers in the COVID-19 group than in the non-COVID19 group. Only one out of 43 positive patients reported to be a current smoker, while $13.7 \%$ of the non-COVID-19 patients announced to smoke regularly by the time of infection. Smoking has been assumed to be possibly associated with adverse disease prognosis, as extensive evidence has highlighted the negative impact of tobacco use on 
Table 2 Comparison of patients with symptoms suspicious for COVID-19 with proven infection vs negative test result

\begin{tabular}{|c|c|c|c|c|}
\hline & All $(n=314)$ & COVID-19 pos. $(n=43)$ & No-COVID-19 $(n=271)$ & $p$ value \\
\hline \multicolumn{5}{|l|}{ Medical history positive for, $n(\%)$} \\
\hline Cardiac & $208(66.5)$ & $28(65.1)$ & $180(66.7)$ & 0.841 \\
\hline Pulmonary & $96(30.7)$ & $10(23.3)$ & $86(31.9)$ & 0.256 \\
\hline LAE/thrombosis & $24(7.7)$ & $2(4.7)$ & $22(8.1)$ & 0.423 \\
\hline Renal & $77(24.6)$ & $4(9.3)$ & $73(27.0)$ & 0.012 \\
\hline Cancer & $84(26.8)$ & $10(23.3)$ & $74(27.4)$ & 0.568 \\
\hline \multicolumn{5}{|l|}{ Smoker, $n(\%)$} \\
\hline Never & $57(18.2)$ & $9(20.9)$ & $48(17.7)$ & 0.611 \\
\hline Yes & $38(12.1)$ & $1(2.3)$ & $37(13.7)$ & 0.034 \\
\hline Quitted & $31(9.9)$ & $3(7.0)$ & $28(10.3)$ & 0.493 \\
\hline Unknown & $188(59.9)$ & $30(16.0)$ & $158(58.3)$ & 0.154 \\
\hline \multicolumn{5}{|l|}{ Symptoms, n (\%) } \\
\hline Dyspnea & $151(48.1)$ & $18(41.9)$ & $133(49.1)$ & 0.379 \\
\hline Sore throat & $26(8.3)$ & $4(9.3)$ & $22(8.1)$ & 0.793 \\
\hline Cough & $134(42.7)$ & $24(55.8)$ & $110(40.6)$ & 0.061 \\
\hline Fever & $172(54.8)$ & $27(62.8)$ & $145(53.5)$ & 0.256 \\
\hline Headache & $26(8.3)$ & $5(11.6)$ & $21(7.7)$. & 0.391 \\
\hline Fatigue & $162(51.6)$ & $22(51.2)$ & $140(51.7)$ & 0.920 \\
\hline Myalgia & $47(15.0)$ & $5(11.6)$ & $42(15.5)$ & 0.509 \\
\hline Chest pain & $22(7.0)$ & $1(2.3)$ & $21(7.7)$ & 0.196 \\
\hline Nausea & $68(21.7)$ & $5(11.6)$ & $63(23.2)$ & 0.086 \\
\hline Diarrhea & $74(23.6)$ & $11(25.6)$ & $63(23.2)$ & 0.738 \\
\hline Dysgeusia & $10(3.2)$ & $6(14.0)$ & $4(1.5)$ & 0.001 \\
\hline \multicolumn{5}{|l|}{ Treatment, $n(\%)$} \\
\hline $\mathrm{O}_{2}$ therapy & $95(30.4)$ & $18(41.9)$ & $77(28.5)$ & 0.077 \\
\hline Ventilator & $12(3.8)$ & $3(7.0)$ & $9(3.3)$ & 0.278 \\
\hline Intensive care & $54(17.2)$ & $4(9.3)$ & $50(18.5)$ & 0.140 \\
\hline Intermediate care & $28(8.9)$ & $4(9.3)$ & $24(8.9)$ & 0.924 \\
\hline Time of admission & $7.3(7.2)$ & $8.6(8.3)$ & $7.1(7.0)$ & 0.214 \\
\hline \multicolumn{5}{|l|}{ Vital parameters } \\
\hline Respiratory rate/min ( \pm SD) & $22( \pm 8)$ & $23( \pm 7)$ & $22( \pm 8)$ & 0.149 \\
\hline Heart rate/min ( \pm SD) & $97( \pm 22)$ & $93( \pm 17)$ & $97( \pm 23)$ & 0.271 \\
\hline Saturation, $\mathrm{O}_{2}$ in \% ( $\left.\pm \mathrm{SD}\right)$ & $94( \pm 7)$ & $95( \pm 4)$ & $94( \pm 7)$ & 0.479 \\
\hline Temperature in ${ }^{\circ} \mathrm{C}( \pm \mathrm{SD})$ & $37.2( \pm 1.3)$ & $37.3( \pm 1.0)$ & $37.2( \pm 1.3)$ & 0.916 \\
\hline BP systolic in mmHg $( \pm$ SD) & $132( \pm 26)$ & $137( \pm 25)$ & $131( \pm 26)$ & 0.172 \\
\hline BP diastolic in mmHg $( \pm \mathrm{SD})$ & $80( \pm 21)$ & $84( \pm 18)$ & $80( \pm 21)$ & 0.250 \\
\hline \multicolumn{5}{|l|}{ Laboratory values } \\
\hline C-reactive protein, mg/L & $8.96( \pm 8.41)$ & $8.28( \pm 5.71)$ & $9.07( \pm 8.78)$ & 0.446 \\
\hline Procalcitonin, $\mu \mathrm{g} / \mathrm{L}( \pm \mathrm{SD})$ & $3.96( \pm 28.26)$ & $0.68( \pm 1.98)$ & $4.51( \pm 30.52)$ & 0.429 \\
\hline Troponin I, $\mu g / L$ ( \pm SD) & $360.42( \pm 3846.98)$ & $81.03( \pm 286.99)$ & $410.94( \pm 4178.37)$ & 0.656 \\
\hline $\mathrm{LDH}, \mathrm{U} / \mathrm{L}( \pm \mathrm{SD})$ & $398.70( \pm 427.95)$ & $435.31( \pm 268.11)$ & $393.03( \pm 447.75)$ & 0.567 \\
\hline Creatinine, mg/dL ( \pm SD) & $1.37( \pm 1.18)$ & $1.20( \pm 0.93)$ & $1.40( \pm 1.22)$ & 0.309 \\
\hline $\mathrm{GFR}, \mathrm{mL} / \mathrm{min}( \pm \mathrm{SD})$ & $56( \pm 23)$ & $59( \pm 21)$ & $55( \pm 23)$ & 0.385 \\
\hline D-dimer, mg/L ( \pm SD) & $4.45( \pm 7.97)$ & $4.52( \pm 8.15)$ & $4.44( \pm 7.96)$ & 0.957 \\
\hline $\mathrm{WBC} / \mathrm{mm}^{3}( \pm \mathrm{SD})$ & $11.25( \pm 14.77)$ & $8.01( \pm 4.24)$ & $11.75( \pm 15.74)$ & 0.127 \\
\hline Lymphocytes $/ \mathrm{mm}^{3}$ ( \pm SD) & $1.96( \pm 7.59)$ & $1.17( \pm 1.44)$ & $2.10( \pm 8.22)$ & 0.538 \\
\hline
\end{tabular}




\section{Symptoms (\%)}

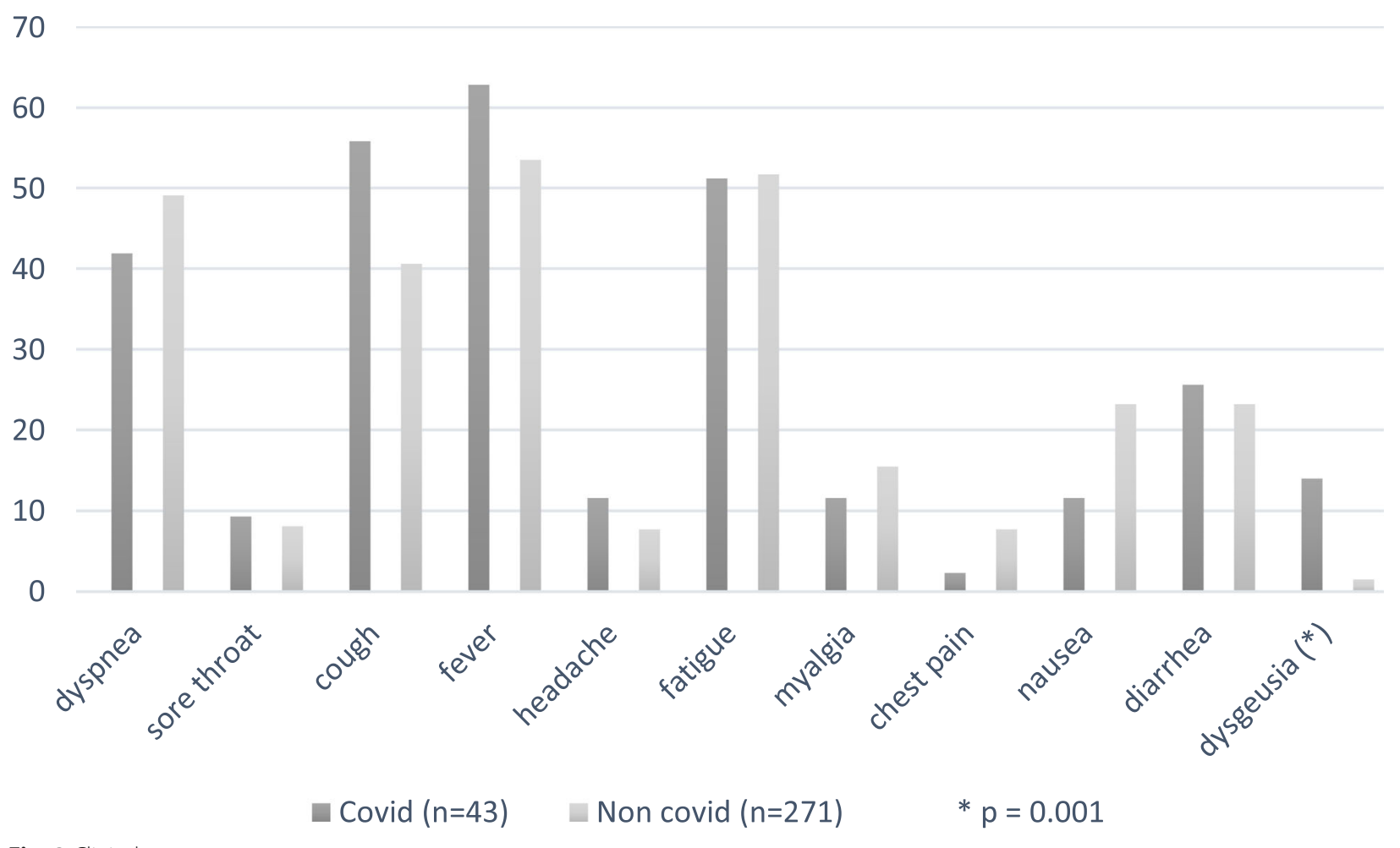

Fig. 3 Clinical symptoms

lung health and previous studies have shown that smokers are more vulnerable to infectious diseases and were also noted to have higher mortality in the previous MERS-CoV outbreak [19, 20]. Most studies examining smoking on patients with COVID-19 assume that smoking is most likely associated with the negative progression and adverse outcomes of COVID-19 [6, 9, 21].

Even during the peak of local pandemia, the rate of proven COVID-19 did not exceed 13.7\% among all patients presenting with suggestive symptoms. We expect this rate to decrease further in the months to come.

Typical ED diagnoses as decompensated heart failure, pneumonia, exacerbated chronic obstructive lung disease, or gastroenteritis present with symptoms suggestive for COVID-19 and can therefore be very misleading. COVID-19 is able to mimic many other common diseases and many unusual clinical presentations have been reported from all over the world [22].

The established workflow of our hospital (Fig. 2) was able to prevent spreading of the virus and thereby protect ED staff and non-COVID-19 patients. Voluntary antibody testing of 316 employees of the university hospital during the peak of the pandemia in Essen revealed only three $\mathrm{AB}$ positive healthcare workers out of 244 exposed high-risk workers (1.2\%) in ED, COVID-19 wards, and COVID-19 ICU as recently published from our institution [23].

Following the high number of patients presenting with possible symptoms of COVID-19 to the ED, only strict isolation and protection measures in line with a broad swab testing will prevent spreading of the virus and maintain safety of ED staff. A validated fast SARS-Cov2-PCR POCT would be extremely helpful to save health care resources.

\section{Limitations}

Our study has few limitations. Data collection was retrospective. Therefore, selection bias and errors in data entry could not be completely excluded. Furthermore, this study is a single-center study, and for these reason, data should not be generalized.

Another limitation is the single testing in SARS-Cov2-negative patients, who mostly got no repeated testing, so there could have been some more SARS-Cov-2-positive patients than numbered.

We often saw patients with advanced disease in our emergency department. Severe disease of COVID-19 often starts in the second week after infection when the 
virus and antigen-antibody complexes affect the lungs and other parts of the body, and viral RNA often cannot be detected in the nasopharyngeal swab [24]. Therefore, a certain number of false negative tests should be taken into account.

Furthermore, we included only inpatient patients. As SARS-Cov-2 is often associated with minor symptoms or illness, the number of outpatient treatment could have been higher than in non-COVID-19 respiratory infections.

In our cohort, the number of patients with unknown smoking status is very high $(59.9 \%)$. Therefore, in this study, it seems to be difficult to evaluate the exact number of current smokers. We think that this might be the reason for the paradoxical finding that a history of smoking was more frequent in the non-COVID-19 group.

\section{Conclusion}

Many severely ill patients presenting to the ED show symptoms suggestive of COVID-19. Even during the peak of pandemia, only $13.7 \%$ (43/314) of these patients proofed positive for COVID-19 in our study. Neither laboratory nor vital parameters nor clinical symptoms can be used to predict COVID-19-positive test results. When present, dysgeusia should raise a high suspicion of COVID-19 during pandemia. Further studies with bigger numbers are needed to evaluate predictors for COVID19 to help to optimize triaging patients in the ED. Strict isolation and personal protection policy together with broad testing of patients under evaluation is needed for the months to come.

\section{Acknowledgements}

We thank all emergency department employees for their great support during hard times.

\section{Authors' contributions}

$D F, D P, A H, B M S, L U, C H$, and JR contributed to the data acquisition. DF, DP, $A H$, and $C K$ contributed to the data analysis. DF, DP, and JR interpreted the data. DF, DP, AH, BMS, LU, CH, SD, CK, and JR drafted the article and substantially revised it. All authors read and approved the final manuscript.

\section{Funding}

Open access funding provided by Projekt DEAL.

\section{Availability of data and materials \\ The anonymized dataset supporting this conclusions is available upon reasonable request from the corresponding author.}

\section{Ethics approval and consent to participate}

Our study was approved by the institutional ethics committee and informed consent was waived (file number: 20-9310-BO, date: 6 May 2020). The study was registered at the German Clinical Trials registry (trial number: DRKS00021675, date 8 May 2020). Patients and the public were not involved in this study.

\section{Consent for publication}

Not applicable

\section{Competing interests}

The authors state that they have no competing interests.

\section{Author details}

${ }^{1}$ Center of Emergency Medicine, University Hospital Essen, Hufelandstrasse 55, 45147 Essen, Germany. ${ }^{2}$ Department of Diagnostic and Interventional Radiology and Neuroradiology, University Hospital Essen, Essen, Germany.

${ }^{3}$ University Hospital Essen, Department of Infectious Diseases, West German Center of Infectious Diseases, University Duisburg-Essen, Essen, Germany.

Received: 19 June 2020 Accepted: 4 August 2020

Published online: 20 August 2020

\section{References}

1. WHO. Coronavirus disease (COVID-2019) situation reports 2020 [Available from: https://www.who.int/docs/default-source/coronaviruse/situationreports/20200607-COVID-19-sitrep-139.pdf?sfvrsn=79dc6d08_2.

2. Wang D, Hu B, Hu C, Zhu F, Liu X, Zhang J, et al. Clinical characteristics of 138 hospitalized patients with 2019 novel coronavirus-infected pneumonia in Wuhan, China. JAMA. 2020;323(11):1061-9.

3. Chan JF, Yuan S, Kok KH, To KK, Chu H, Yang J, et al. A familial cluster of pneumonia associated with the 2019 novel coronavirus indicating personto-person transmission: a study of a family cluster. Lancet. 2020;395(10223): 514-23.

4. Bajema KL, Oster AM, McGovern OL, Lindstrom S, Stenger MR, Anderson TC, et al. Persons evaluated for 2019 novel coronavirus - United States, January 2020. MMWR Morb Mortal Wkly Rep. 2020;69(6):166-70.

5. Wu Z, McGoogan JM. Characteristics of and important lessons from the coronavirus disease 2019 (COVID-19) outbreak in China: summary of a report of 72314 cases from the Chinese Center for Disease Control and Prevention. JAMA. 2020;323(13):1239-42.

6. W-j G, Ni Z-y, Hu Y, Liang W-h, Ou C-q, He J-x, et al. Clinical characteristics of coronavirus disease 2019 in China. N Engl J Med. 2020;382(18):1708-20.

7. Wichmann D, Sperhake JP, Lütgehetmann M, et al. Autopsy findings and venous thromboembolism in patients with COVID-19. Ann Intern Med. 2020. p. M20-2003. https://doi.org/10.7326/M20-2003. [published online ahead of print, 2020 May 6].

8. Giacomelli A, Pezzati L, Conti F, et al. Self-reported olfactory and taste disorders in patients with severe acute respiratory coronavirus 2 infection: a cross-sectional study. Clin Infect Dis. 2020;71(15):889-90. https://doi.org/10. 1093/cid/ciaa330.

9. Zhou F, Yu T, Du R, Fan G, Liu Y, Liu Z, et al. Clinical course and risk factors for mortality of adult inpatients with COVID-19 in Wuhan, China: a retrospective cohort study. Lancet. 2020;395(10229):1054-62.

10. Wu C, Chen X, Cai Y, et al. Risk factors associated with acute respiratory distress syndrome and death in patients with coronavirus disease 2019 pneumonia in Wuhan, China. JAMA Intern Med. 2020;180(7):1-11. https:// doi.org/10.1001/jamainternmed.2020.0994.

11. Corman VM, Landt O, Kaiser M, Molenkamp R, Meijer A, Chu DK, et al. Detection of 2019 novel coronavirus (2019-nCoV) by real-time RT-PCR. Eurosurveillance. 2020;25(3):2000045.

12. Gao Y, Li T, Han M, et al. Diagnostic utility of clinical laboratory data determinations for patients with the severe COVID-19. J Med Virol.2020; 92(7):791-6. https://doi.org/10.1002/jmv.25770.

13. Fan BE, Chong VCL, Chan SSW, Lim GH, Lim KGE, Tan GB, et al. Hematologic parameters in patients with COVID-19 infection. Am J Hematol. 2020;95(6): E131-E4.

14. Mardani R, Ahmadi Vasmehjani A, Zali F, Gholami A, Mousavi Nasab SD, Kaghazian $\mathrm{H}$, et al. Laboratory parameters in detection of COVID-19 patients with positive RT-PCR; a diagnostic accuracy study. Arch Acad Emerg Med. 2020;8(1):e43.

15. Lechien JR, Chiesa-Estomba CM, De Siati DR, et al. Olfactory and gustatory dysfunctions as a clinical presentation of mild-to-moderate forms of thecoronavirus disease (COVID-19): a multicenter European study. Eur Arch Otorhinolaryngol. 2020;277(8):2251-61. https://doi.org/10.1007/s00405-02005965-1.

16. Luers JC, Rokohl AC, Loreck N, Wawer Matos PA, Augustin M, Dewald F, Klein F, Lehmann C, Heindl LM. Olfactory and Gustatory Dysfunction in Coronavirus Disease 19 (COVID-19). Clinical infectious diseases: an official 
publication of the Infectious Diseases Society of America, ciaa525. Advance online publication. 2020. https://doi.org/10.1093/cid/ciaa525.

17. Mahmoodi BK, Matsushita K, Woodward M, Blankestijn PJ, Cirillo M, Ohkubo $T$, et al. Associations of kidney disease measures with mortality and endstage renal disease in individuals with and without hypertension: a metaanalysis. Lancet. 2012;380(9854):1649-61.

18. Gao C, Cai Y, Zhang K, Zhou L, Zhang Y, Zhang X, et al. Association of hypertension and antihypertensive treatment with COVID-19 mortality: a retrospective observational study. Eur Heart J. 2020;41(22):2058-66.

19. Park J-E, Jung S, Kim A, Park J-E. MERS transmission and risk factors: a systematic review. BMC Public Health. 2018;18(1):574.

20. Tonnesen P, Marott IL, Nordestgaard B, Bojesen SE, Lange P. Secular trends in smoking in relation to prevalent and incident smoking-related disease: A prospective population-based study. Tob Induc Dis. 2019;17:72.

21. Zhang JJ, Dong X, Cao YY, et al. Clinical characteristics of 140 patients infected with SARS-CoV-2 in Wuhan, China. Allergy. 2020;75(7):1730-41. https://doi.org/10.1111/all.14238.

22. Chen N, Zhou M, Dong X, Qu J, Gong F, Han Y, et al. Epidemiological and clinical characteristics of 99 cases of 2019 novel coronavirus pneumonia in Wuhan, China: a descriptive study. Lancet (London, England). 2020; 395(10223):507-13.

23. Korth J, Wilde B, Dolff S, Anastasiou OE, Krawczyk A, Jahn M, et al. SARSCoV-2-specific antibody detection in healthcare workers in Germany with direct contact to COVID-19 patients. J Clin Virol. 2020;128:104437.

24. Ai T, Yang Z, Hou H, et al. Correlation of Chest CT and RT-PCR Testing for Coronavirus Disease 2019 (COVID-19) in China: A Report of 1014 Cases. Radiology. 2020;296(2):E32-40. https://doi.org/10.1148/radiol.2020200642.

\section{Publisher's Note}

Springer Nature remains neutral with regard to jurisdictional claims in published maps and institutional affiliations.

Ready to submit your research? Choose BMC and benefit from:

- fast, convenient online submission

- thorough peer review by experienced researchers in your field

- rapid publication on acceptance

- support for research data, including large and complex data types

- gold Open Access which fosters wider collaboration and increased citations

- maximum visibility for your research: over $100 \mathrm{M}$ website views per year

At $\mathrm{BMC}$, research is always in progress.

Learn more biomedcentral.com/submissions 